\title{
Monitoring of Intraperitoneal Fluid Volume during Peritoneal Equilibration Testing using Segmental Bioimpedance
}

\author{
Fansan Zhu ${ }^{a}$ Samer R. Abbas ${ }^{a}$ Roxana M. Bologab Nathan W. Levin ${ }^{a}$ \\ Peter Kotanko ${ }^{a, c}$ \\ ${ }^{a}$ Renal Research Institute, New York, NY, USA;

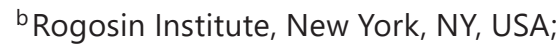 \\ 'Icahn School of Medicine at Mount Sinai, New York, NY, USA
}

\author{
Keywords \\ Ultrafiltration volume $\cdot$ Bioimpedance $\cdot$ Peritoneal membrane $\cdot$ Peritoneal dialysis . \\ Ultrafiltration failure
}

\begin{abstract}
Background: Ultrafiltration failure and fluid overload are common in peritoneal dialysis (PD) patients. Knowledge of intraperitoneal volume (IPV) and time to peak IPV during a dwell would permit improved PD prescription. This study aimed to utilize trunk segmental bioimpedance analysis (SBIA) to quasi-continuously monitor IPV (IPV $V_{S B I A}$ ) during the peritoneal dwell. Methods: IPV $V_{S B I A}$ was measured every minute using lower-trunk SBIA (Hydra 4200; Xitron Technologies Inc., CA, USA) in 10 PD patients during a standard 240-min peritoneal equilibration test $(P E T)$. The known dialysate volume $(2 \mathrm{~L})$ rendered IPV $\mathrm{SBIA}_{\mathrm{A}}$ calibration and calculation of instantaneous ultrafiltration volume $\left(\mathrm{UFV}_{\text {SBIA }}\right)$ possible. $\mathrm{UFV}_{\text {SBIA }}$ was defined as $I_{\text {IPVIA }}-2$ L. Results: Based on dialysate-to-plasma creatinine ratio, 2 patients were high, 7 high-average, and 1 low-average transporters. Technically sound IPV SBIA $_{\text {measurements }}$ were obtained in 9 patients (age $59.0 \pm 8.8$ years, 7 females, 5 African Americans). Drained ultrafiltration volume $\left(\mathrm{UFV}_{\text {drain }}\right)$ was $0.47 \pm 0.21 \mathrm{~L}$ and correlated $(r=0.74 ; p<0.05)$ with enddwell UFV SBIA $(0.55 \pm 0.17 \mathrm{~L})$. Peak UFV $\mathrm{SBIA}_{\text {Sas }} 1.04 \pm 0.32 \mathrm{~L}$, it was reached $177 \pm 61$ min into the dwell and exceeded end-dwell UFV $\mathrm{SBIA}_{\text {by }} 0.49 \pm 0.28 \mathrm{~L}(95 \% \mathrm{Cl}: 0.27-0.7)$ and UFV $\mathrm{Crain}_{\text {by }}$ $0.52 \pm 0.31 \mathrm{~L}(95 \% \mathrm{Cl}: 0.29-0.76)$, respectively. Conclusion: This pilot study demonstrates the feasibility of trunk segmental bioimpedance to quasi-continuously monitor IPV $V_{S B I A}$ and identify the time to peak UFV $V_{S B I A}$ during a standard PET. Such new insights into the dynamics of intraperitoneal fluid volume during the dwell may advance our understanding of the underlying transport physiology and eventually assist in improving PD treatment prescriptions.
\end{abstract}




\section{Kidney \\ Blood Pressure \\ Research}

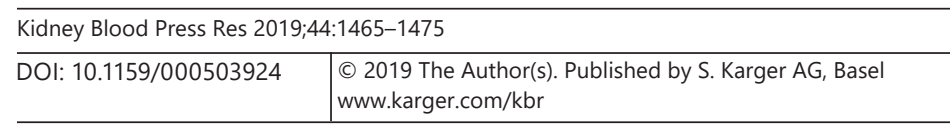

Zhu et al.: Intraperitoneal Volume Monitoring

\section{Background}

Recent studies have shown that $25-70 \%$ of peritoneal dialysis (PD) patients experience fluid overload [1]. Its prevalence is due to many factors, including a decline in residual renal function, high salt and water intake, chronic inflammation, poor nutritional status, and small solute transport characteristics. Fast transporters are especially prone to fluid overload given the rapid dissipation of the peritoneal-to-plasma glucose gradient after instillation of dialysis solution, resulting in potential ultrafiltration failure during longer dwells [2, 3]. Improved knowledge of the time course of intraperitoneal volume (IPV) during PD dwells may provide insights into fluid transport characteristics beyond the information provided by a standard peritoneal equilibration test (PET) and may eventually help to optimize and personalize PD prescriptions. Although ultrasound studies can provide a snapshot image of IPV, they are not practical for continuous IPV monitoring.

Bioimpedance analysis (BIA) has been used for many years to measure fluid volumes in body compartments. Information from BIA can provide useful information on the fluid status [4-8]. However, due to fundamental physical and technical issues, standard BIA has not been able to measure fluid volume in the peritoneal cavity. To overcome that limitation, we developed an abdominal segmental BIA (SBIA) technique that allows for quantitative

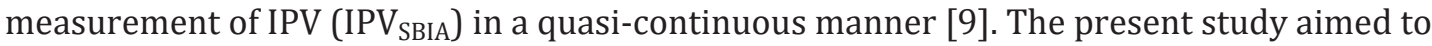
explore the potential usefulness of IPV measurements and to relate IPV dynamics to transport characteristics obtained from standard 240-min PET.

\section{Methods}

\section{Study Population}

Ten PD patients were studied during routine PET at the Rogosin Institute in New York. The following inclusion criteria were applied:

1. Age $\geq 18$ and $\leq 80$ years

2. PD vintage $\geq 3$ months

3. Clinically stable, with no acute medical problems in the preceding 3 months

4. Willing and able to provide informed consent

Patients with $\geq 1$ of the following criteria were excluded:

1. Acute medical problems in the preceding 3 months

2. Simultaneous participation in another clinical study (except observational trials)

3. Psychological conditions which could interfere with the patient's ability to comply with or understand the study protocol

4. Pregnancy

5. Limb amputation

6. Presence of a pacemaker, implantable pump, or artificial joint

7. Hepatitis B, hepatitis C, or human immunodeficiency virus (HIV) infection

8. Inability to provide informed consent

\section{Peritoneal Equilibration Test}

Segmental bioimpedance analysis was performed during a standard 240-min PET using $2 \mathrm{~L}$ of dialysate containing $2.5 \mathrm{~g} / \mathrm{dL}$ dextrose $(2.26 \mathrm{~g} / \mathrm{dL}$ glucose $)$. Serum and dialysate creatinine levels were measured 0,120, and $240 \mathrm{~min}$ after PET fill infusion. Patients were stratified into peritoneal membrane transport groups based on the creatinine dialysate/plasma (D/P). Dialysate glucose levels were measured in 10-mL samples at 0, 60, 120, 180, and 240 min (in total $40 \mathrm{~mL}$ during the PET). Upon removal of the final $10-\mathrm{mL}$ sample at $240 \mathrm{~min}$, the dialysate 
Fig. 1. Measurement of segmental bioimpedance in the peritoneal cavity; electrode placement: $\mathrm{I}_{1}$ and $\mathrm{I}_{2}$ were placed on the hands $\left(\mathrm{I}_{1 \mathrm{~L}}\right.$ and $\left.\mathrm{I}_{1 \mathrm{R}}\right)$ and feet $\left(\mathrm{I}_{2 \mathrm{~L}}\right.$ and $\left.\mathrm{I}_{2 \mathrm{R}}\right)$, respectively, for injecting current; 2 paired electrodes $\left(\mathrm{S}_{1}-\mathrm{S}_{2}\right.$ and $S_{3}-S_{4}$ ) were placed at the level of the 10th rib and the buttock on both sides, respectively, for resistance measurements.

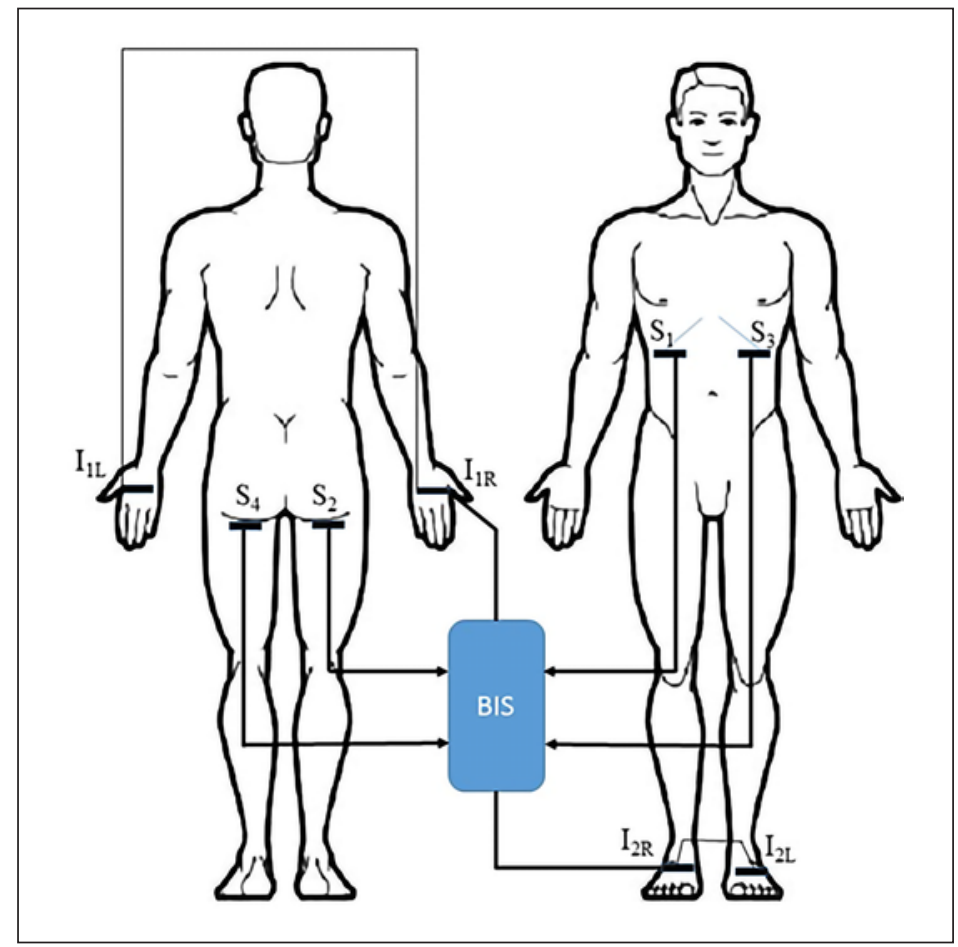

was drained and weighed. The drained ultrafiltrate volume $\left(\mathrm{UFV}_{\mathrm{drain}}\right)$ was calculated as the weight difference between the instilled and drained dialysate. For these calculations, the density of both fluids was assumed to be $1 \mathrm{~kg} / \mathrm{L}$, so that $1 \mathrm{~kg}=1 \mathrm{~L}$.

\section{Bioimpedance Measurements}

The Hydra 4200 device (Xitron Technologies Inc., San Diego, CA, USA) was used. Lowertrunk segmental bioimpedance measurements were made once a minute during the PET. Eight electrodes were placed as shown in Figure 1. To deliver the bioimpedance current, 2 electrodes were placed on the hands $\left(\mathrm{I}_{1 \mathrm{R}}\right.$ and $\left.\mathrm{I}_{1 \mathrm{~L}}\right)$ and 2 on the feet $\left(\mathrm{I}_{2 \mathrm{R}}\right.$ and $\left.\mathrm{I}_{2 \mathrm{~L}}\right)$. To measure resistance and reactance, 2 paired electrodes were placed on each side of the body $\left(\mathrm{S}_{1}-\mathrm{S}_{2}\right.$ and $S_{3}-S_{4}$ ) with one member of each pair at the 10th rib and the other just below the buttocks. Segmental resistance at $5 \mathrm{kHz}\left(\mathrm{R}_{5}\right.$, in $\left.\Omega\right)$ was computed from the multifrequency data as previously described [9]. Five to $10 \mathrm{~min}$ after the patient had moved into a supine position, the BIA measurement started, and after a further 5 min of baseline BIA measurements, the peritoneal cavity was filled with PD dialysate. The BIA measurement was continued throughout the entire 4-h dwell and ended after completion of the dialysate drain. Patients were asked to maintain a supine position during the entire measurement period.

\section{Study Procedure and Measurements}

Step 1. A baseline impedance measurement of the empty ("dry") peritoneal cavity was obtained. For subsequent calculations, this baseline calculation of IPV was set to zero.

Step 2. The peritoneal cavity was filled with $2 \mathrm{~L}$ of dialysis solution. Once filling was initiated, impedance was recorded every minute. The change in resistance $\left(\Delta R_{5}\right)$ between baseline peritoneal volume and filled volume (promptly after completion of the instillation) was calculated. The ratio of resistances between empty and filled states was calculated, and

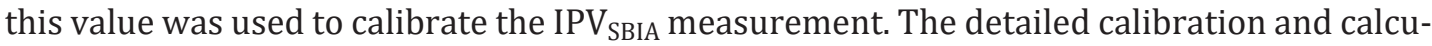
lation procedures have been reported previously [9]. 
Fig. 2. Indicators used to describe $\mathrm{IPV}_{\text {SBIA }}$ dynamics during PET. This curve has been smoothed from raw data (GraphPad Prism 5).

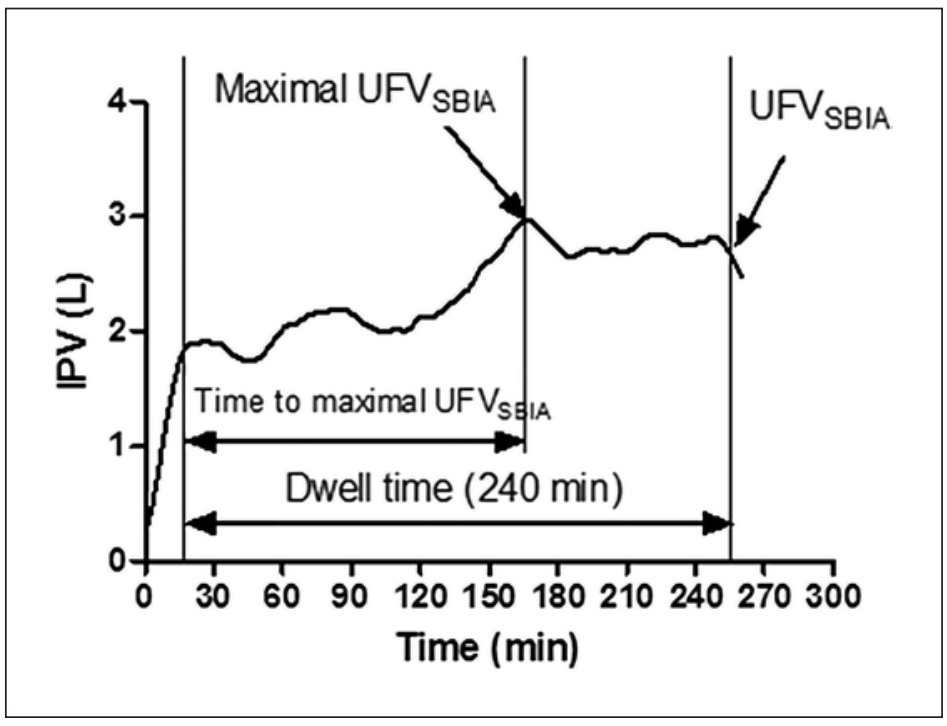

Step 3. Peritoneal fluid volumes were recorded using SBIA in 1-min intervals throughout the 240-min PET.

Step 4. At $240 \mathrm{~min}$, the dialysate was drained and weighed.

The following peritoneal fluid volume-related parameters were measured and analyzed (Fig. 2):

- Area under the curve (AUC; expressed as $\mathrm{L} \times \mathrm{min}$ ) of the $\mathrm{IPV}_{\text {SBIA }}$ over time was calculated using the initial "empty" value as a zero baseline. The curve was smoothed using a moving average with a window width of 5 min (GraphPad; GraphPad Software Inc., La Jolla, CA, USA).

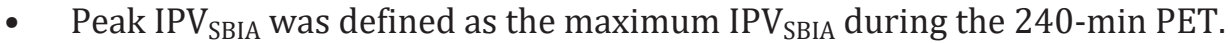

- Time-to-peak IPV $V_{\text {SBIA }}$ was taken to be the time between start of infusion and the time of maximum IPV $\mathrm{SBIA}_{\text {. }}$

- Bioimpedance-measured UFV (UFV $V_{\text {SBIA }}$ ) was calculated as the $\mathrm{IPV}_{\text {SBIA }}-2 \mathrm{~L}$ (initial dialysate volume). We then added the volume of the peritoneal fluid samples drawn during the dwell (in total $40 \mathrm{~mL}$, the volume of the four 10 - $\mathrm{mL}$ intradialytic dialysate samples).

- Other parameters measured were systolic and diastolic blood pressures, heart rate, height, and pre- and post-PET body weight. Additional demographic and disease-related characteristics recorded were cause of renal failure, PD vintage (years on PD), and diabetes status; these were obtained from patient health records.

\section{Data Analysis}

Data are presented as means and $\mathrm{SD}$, or percent. Values for $\mathrm{UFV}_{\mathrm{SBIA}}$, maximal $\mathrm{IPV}_{\mathrm{SBIA}}$, IPV $_{\text {SBIA }}$ AUC, and time to peak IPV $V_{\text {SBIA }}$ were calculated for each patient. Patient results were categorized by peritoneal transport status. A $p$ value $<0.05$ was considered significant.

\section{Results}

The baseline characteristics of the 10 patients studied are shown in Table 1. Per PET $\mathrm{D} / \mathrm{P}$ creatinine, 2 patients were classified as high transporters (D/P creatinine 0.82 and 0.83 , respectively), 7 as high-average transporters (D/P creatinine ranging from 0.66 to 0.79 ), and 1 as low-average transporter (D/P creatinine 0.59 ). Per PET D/ $\mathrm{D}_{0}$ glucose (ratio 
Kidney

Blood Pressure

Research

Table 1. Patient baseline characteristics $(n=10)$

\begin{tabular}{l|l}
\hline \multicolumn{2}{l}{ Kidney Blood Press Res 2019;44:1465-1475 } \\
\hline DOI: 10.1159/000503924 & $\begin{array}{l}\text { (c) 2019 The Author(s). Published by S. Karger AG, Basel } \\
\text { www.karger.com/kbr }\end{array}$ \\
\hline
\end{tabular}

Zhu et al.: Intraperitoneal Volume Monitoring

\begin{tabular}{lcc}
\hline & Mean $\pm \mathrm{SD} / n$ & Range \\
\hline Females/males, $n$ & $7 / 3$ & \\
Race, $n$ & & \\
African American & 5 & \\
Caucasian & 3 & \\
Diabetes mellitus, $n$ & 3 & $46-80$ \\
Age, years & $59.0 \pm 8.8$ & $1-8.5$ \\
PD vintage, years & $4.6 \pm 2.9$ & $151-174$ \\
Height, cm & $161.9 \pm 7.9$ & $51.6-91.6$ \\
Weight, kg & $69.8 \pm 12.4$ & $21.8-38.4$ \\
Body mass index, kg/m ${ }^{2}$ & $26.7 \pm 5.1$ & $93-178$ \\
Systolic blood pressure, mm Hg & $143.3 \pm 21.9$ & $62-95$ \\
Diastolic blood pressure, mm Hg & $80.8 \pm 11$ & $63-93$ \\
Heart rate, beats/min & $78.3 \pm 10$ & $132-138$ \\
Serum sodium, mEq/L & $135.1 \pm 1.9$ & $3-5.5$ \\
Serum potassium, mEq/L & $4.1 \pm 0.9$ & $25-104$ \\
Blood urea nitrogen, mg/dL & $62.9 \pm 23.1$ &
\end{tabular}

Table 2. Membrane transport characteristics

\begin{tabular}{|c|c|c|c|c|c|c|c|c|}
\hline $\begin{array}{l}\text { Patient } \\
\text { No. }\end{array}$ & $\begin{array}{l}\mathrm{D} / \mathrm{P} \\
\text { creatinine }\end{array}$ & High & $\begin{array}{l}\text { High } \\
\text { average }\end{array}$ & $\begin{array}{l}\text { Low } \\
\text { average }\end{array}$ & $\begin{array}{l}\text { D4/D0 } \\
\text { glucose }\end{array}$ & High & $\begin{array}{l}\text { High } \\
\text { average }\end{array}$ & $\begin{array}{l}\text { Low } \\
\text { average }\end{array}$ \\
\hline 1 & 0.82 & $\mathrm{x}$ & & & 0.25 & $\mathrm{x}$ & & \\
\hline 2 & 0.79 & & $\mathrm{x}$ & & 0.26 & & $\mathrm{x}$ & \\
\hline 3 & 0.59 & & & $\mathrm{x}$ & 0.34 & & $\mathrm{x}$ & \\
\hline 4 & 0.67 & & $\mathrm{x}$ & & 0.29 & & $\mathrm{x}$ & \\
\hline 5 & 0.83 & $\mathrm{x}$ & & & 0.22 & $\mathrm{x}$ & & \\
\hline 6 & 0.69 & & $\mathrm{x}$ & & 0.32 & & $\mathrm{x}$ & \\
\hline 7 & 0.67 & & $\mathrm{x}$ & & 0.26 & & $\mathrm{x}$ & \\
\hline 8 & 0.72 & & $\mathrm{x}$ & & 0.28 & & $\mathrm{x}$ & \\
\hline 9 & 0.74 & & $\mathrm{x}$ & & 0.30 & & $\mathrm{x}$ & \\
\hline 10 & 0.66 & & $\mathrm{x}$ & & 0.34 & & $\mathrm{x}$ & \\
\hline
\end{tabular}

of final-to-initial dialysate glucose concentrations), 2 patients were classified as high transporters $\left(\mathrm{D} / \mathrm{D}_{0}\right.$ glucose of 0.22 and 0.25 , respectively) and 8 as high-average transporters $\left(\mathrm{D} / \mathrm{D}_{0}\right.$ glucose ranging from 0.26 to 0.34 ). Table 2 shows the individual patients' transport characteristics.

Measurements of intraperitoneal fluid volumes were successful in 9 patients and failed in 1 patient due to technical reasons. Figure 3 shows the IPV $V_{\text {SBIA }}$ recordings in these 9 patients, and the respective IPV $_{\text {SBIA }}$ AUC calculations.

Figure 4 shows values of $U_{F V} V_{\text {SBIA }}$, maximal $U_{F V} V_{\text {SBIA }}$, the IPV $V_{\text {SBIA }}$ AUC, and time to peak $\mathrm{UFV}_{\text {SBIA }}$ in 9 patients stratified by peritoneal membrane transport status. Lower $\mathrm{UFV}_{\text {SBIA }}$, peak $\mathrm{UFV}_{\text {SBIA }}$, and IPV $\mathrm{V}_{\text {SBIA }}$ AUC were associated with a high transport status, while high $\mathrm{UFV}_{\text {SBIA }}$, maximal $U_{F V} V_{\text {SBIA }}$, and $I_{P V} V_{\text {SBIA }}$ AUC were associated with a low transport status.

Peak $U_{F V} V_{\text {SBIA }}$ was $1.04 \pm 0.32 \mathrm{~L}$ and was attained $177 \pm 61 \mathrm{~min}$ into the dwell; it exceeded the end-dwell UFV SBIA $_{\text {by }} 0.49 \pm 0.28 \mathrm{~L}(95 \%$ CI: $0.27-0.7)$ and UFV $_{\text {drain }}$ by $0.52 \pm 0.31 \mathrm{~L}(95 \%$ CI: 0.29-0.76), respectively (Fig. 4a-c). Time-to-peak IPV SBIA $_{\text {as }}$ wot related to transport status. Figure 5 shows the average IPV $_{\text {SBIA }}$ curve in 9 patients with $95 \%$ CIs. 


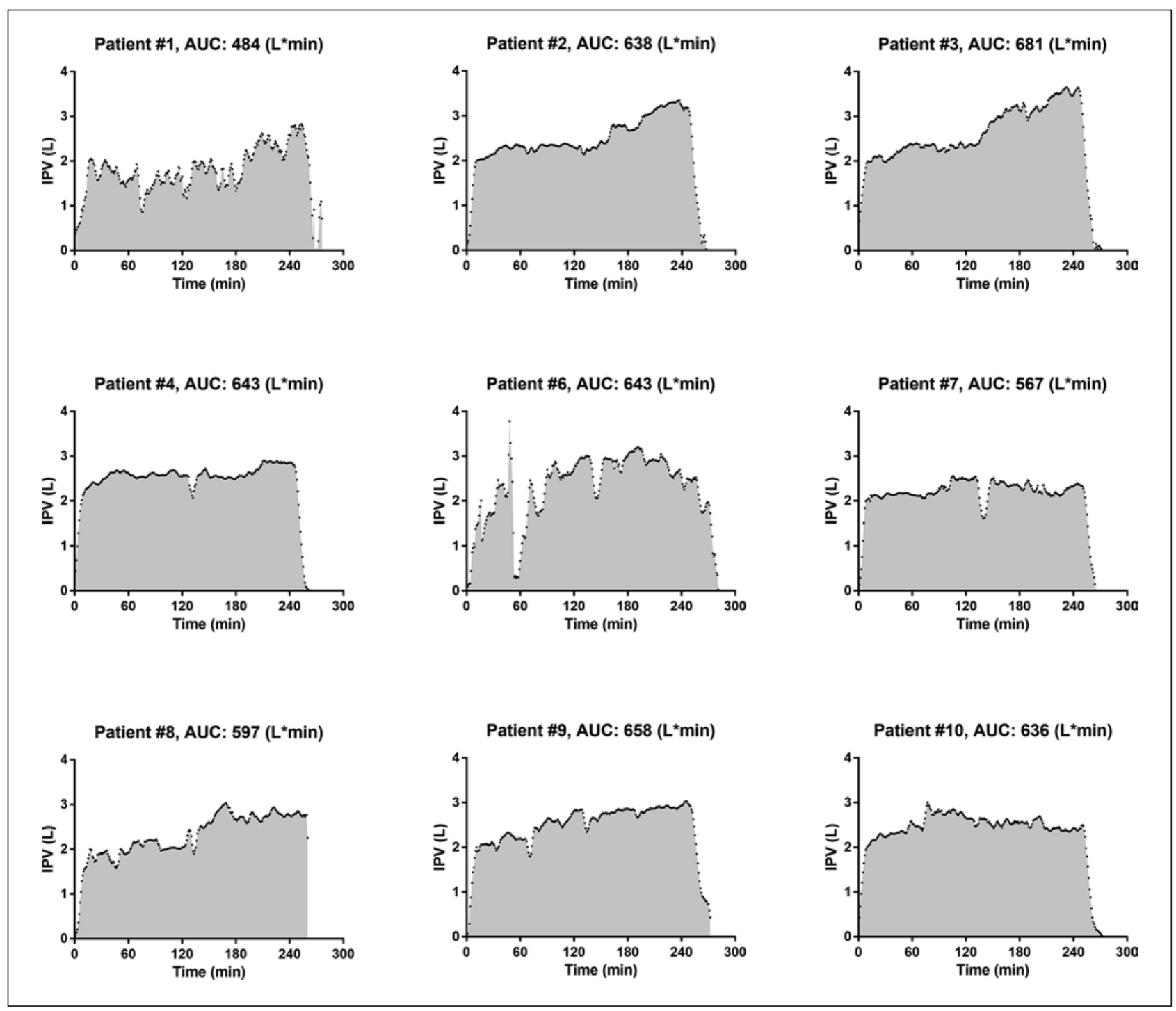

Fig. 3. Area under curve (AUC) of the intraperitoneal volume (IPV $\mathrm{SBIA}_{\mathrm{A}}$ ) during PET in 9 individual patients. One patient (\#5) was excluded because of technical failure of the bioimpedance measurements.

\section{Discussion}

This pilot study demonstrates the feasibility of segmental bioimpedance measurements to continuously monitor changes in intraperitoneal fluid volume during a PD dwell. This novel technique permits characterization of intraperitoneal fluid volume changes during a dwell, including various patterns of volume changes that may be patient specific. Such new insights into the dynamics of intraperitoneal fluid volume during the dwell may advance our understanding of the underlying transport physiology and eventually assist in improving PD treatment prescription.

Fluid management is a clinical challenge in PD patients [1], and recent studies have indicated the presence of fluid overload in a substantial fraction. In the EuroBCM study, wholebody bioimpedance spectroscopy was used to assess volume status in a cross-sectional cohort of prevalent PD patients in 28 centers in 6 European countries [10]. The Initiative for Patient 


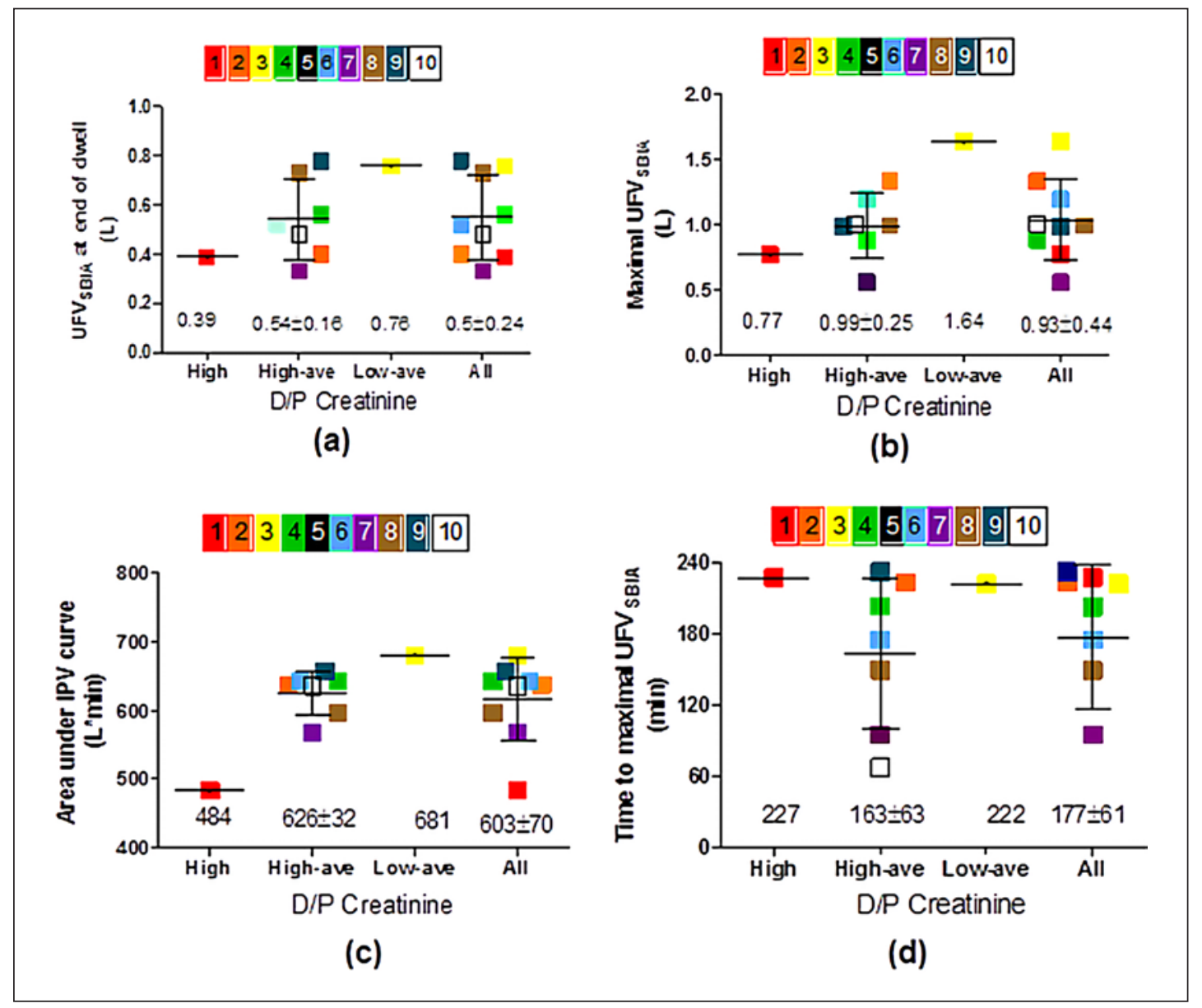

Fig. 4. $U F V_{\text {SBIA }}$ at the end of dwell (a), maximal $U_{F V} V_{\text {SBIA }}(\mathbf{b})$, area under IPV curve (c), and time to maximal $\mathrm{UFV}_{\text {SBIA }}$ (d) in patients stratified by peritoneal transport status. Average maximal $\mathrm{UFV}_{\mathrm{SBIA}}$ at $177 \pm 61 \mathrm{~min}$ was significantly larger than the $\mathrm{UFV}_{\mathrm{SBIA}}$ at $240 \mathrm{~min}(0.93 \pm 0.44$ vs. $0.5 \pm 0.24 \mathrm{~L}, p<0.01)$. High, High-ave, and Low-ave represent the transport status by dialysate/plasma creatinine. Individual patients from \#1 to \#10 are indicated by different colors. Patient \#5 has been omitted due to technical failure of the bioimpedance measurements.

Outcomes in Dialysis-Peritoneal Dialysis (IPOD-PD) study of 1,092 incident PD patients from 135 centers in 32 countries found that $56.4 \%$ of patients were fluid overloaded before PD was initiated. These findings are in line with reports from China which reported $66.8 \%$ continuous ambulatory PD patients with fluid overload [11]. Observational studies have shown that there is no difference in volume control in patients on automated PD versus continuous ambulatory PD [12]. A recent publication reports a relationship between weight gain and maximum ultrafiltration rate [13]. In patients with fluid overload, the identification of both the magnitude and the timing of maximal UFV (IPV - instilled dialysate volume) during the dwell may assist with achieving better volume control. Bioimpedance is the only currently available, clinically viable technique for continuous measurements of IPV changes. Current clinical studies of bioimpedance in PD patients focus on fluid management and body composition [14-16]. The root cause of fluid overload in PD patients is low UFV. Therefore, increase in UFV is the fundamental solution for poor fluid management in PD treatment. Our 2 previous studies have shown the potential feasibility of using segmental bioimpedance to measure IPV $[9,17]$. The present study adds a new dimension, because for the first time we were able to 
Fig. 5. Average intraperitoneal volume (IPV $\left.\mathrm{SBIA}_{\mathrm{A}}\right)$ in 10 -min increments in 9 patients during PET. The bars represent $95 \%$ confidence intervals.

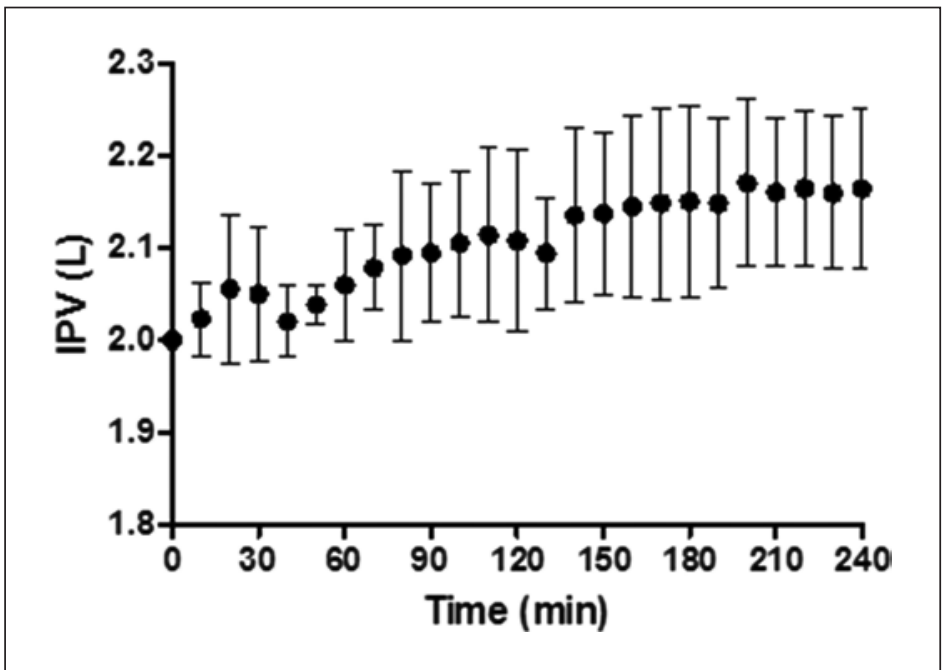

relate membrane transport characteristics to the time-to-peak IPV. With this technique, bioimpedance measurements are taken before and after instillation of a known volume of fluid into the peritoneal cavity, and this information is used to calibrate the bioimpedance estimate of the volume. Continuous measurement of IPV based on the known ratio of volume change to resistance changes then permits recognition of both the shape of the volume curve over time and the time-to-peak IPV, at which point the fluid could optimally be drained. In addition, the average IPV curve in 9 patients demonstrates dynamic IPV changes (Fig. 5). As far as we know, this is the first time to report that IPV changes have been observed during PET. Unlike modeling studies, this method enables us to observe the real nature of net IPV changes.

It is obvious that SBIA adds to the currently available repertoire of diagnostic tests to assess membrane and transport characteristics in PD patients. The modified ("two in one") PET uses a standard PET (4-h dwell) followed by a mini PET (1-h dwell) with the same glucose concentration (3.86\%) [18] or with different glucose concentrations in 2 exchanges [19]. The "two in one" PET can quickly and simply evaluate membrane transport characteristics and free water removal in the first hour. However, the first hour of dwell might not be able to predict the time to peak UFV. In this paper, the time to peak UFV was $177 \pm 61 \mathrm{~min}$. Clearly, current test methods lack the ability to follow the change in UFV dynamically with a 1-min signal resolution.

Segmental PD BIA does suffer from shortcomings, which must be resolved, e.g., the need for an almost static body position (supine in our patients). It is difficult to motivate patients to remain in a specific position for hours. Unless future developments of segmental PD BIA can address that inconvenience, the method is not likely to gain widespread acceptance. Potential solutions may come from "smart textiles" with integrated sensors or small adhesive skin patches that have all the necessary technology onboard [20].

Segmental PD BIA may have clinical application beyond the identification of peak UFV. For example, peritoneal overfill is a well-recognized problem in patients treated with automated PD or continuous-flow PD [21, 22]. Such overfill events could be identified and prevented with segmental PD BIA in place.

Apart from its potential clinical usefulness, results obtained from an IPV over time profile could be used to compare and help validate various mathematical models of peritoneal fluid transport; while these models have provided many useful simulations, they require confirmation by in vivo measurements in a clinical setting [23]. 


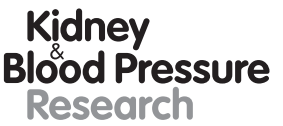

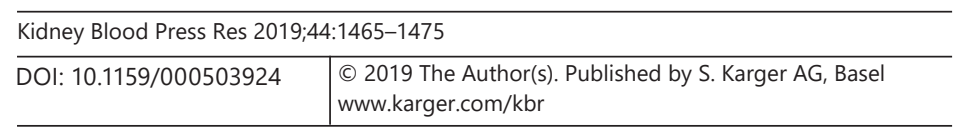

Zhu et al.: Intraperitoneal Volume Monitoring

Relationship of Transport Status to UFV BIA

The results of this study suggest a relationship between D/P creatinine transport status and $U_{F V} V_{\text {SBIA }}, I_{\text {SBIA }}$ AUC, and time-to-peak UFV with the results of previous research that has investigated the relationship between transport status and UFV [24, 25]. Our study found high creatinine transport status to be

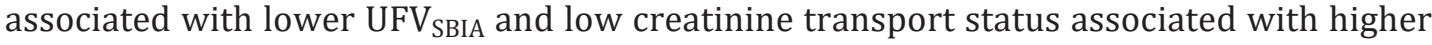
$\mathrm{UFV}_{\text {SBIA }}$, as previously described [26]. This additional information could facilitate better understanding of UFV dynamics and improved the clinical prescription of PD for individual patients.

In addition to the above, the results of this study may inspire the development of new techniques to examine the characteristics of the peritoneal membrane, including the measurement of changes in peritoneal cavity fluid volume over time, eliminating the need for repeat PETs.

A limitation of this study is its small number of patients, especially those with low and high transporter status. In addition, the continuous BIA technique used requires improvements to reduce the impact of patient movements on the BIA signal; a simple and stable electrode system and more advanced signal processing methods need to be developed. These technical requirements may be the major obstacle for its slow application since our first publication in 2003.

\section{Conclusions}

This study demonstrates a new technique for monitoring changes in peritoneal cavity fluid volume during PD. The UFV profiles can be used to identify maximal IPV during a dwell, allowing for optimization of drain times for individual patients. This should result in larger net fluid removal. While these early results are encouraging, additional validation studies are indicated. Other required advances that would add value to our technique include the development of an algorithm to automatically detect maximum $U_{F V} V_{\text {SBIA }}$ and methods to improve the convenience of measurement.

\section{Acknowledgments}

Part of the results from this study were presented at the Annual Meeting of the American Society of Nephrology 2017 in New Orleans. The authors thank Bambi Lanto for her performing PET. S.R.A. was supported by the nephrocore Fresenius Medical Care exchange program for young scientists. The authors thank Sarunas Daugirdas for editing the language of the paper.

\section{Statement of Ethics}

The study protocol was approved by the Weill Cornell Medical College (WCMC) Institutional Review Board. All patients gave informed consent prior to the study.

\section{Disclosure Statement}

P.K. and N.W.L. hold stock in Fresenius Medical Care. P.K. receives author honoraria from UpToDate. The other authors have no conflicts of interest to declare. 


\section{Kidney \\ Blood Pressure Research}

\begin{tabular}{l|l}
\hline Kidney Blood Press Res 2019;44:1465-1475 \\
\hline DOI: 10.1159/000503924 & $\begin{array}{l}\text { @ 2019 The Author(s). Published by S. Karger AG, Basel } \\
\text { www.karger.com/kbr }\end{array}$ \\
\hline
\end{tabular}

Zhu et al.: Intraperitoneal Volume Monitoring

\section{Funding Sources}

No funding was obtained for this study.

\section{Author Contributions}

F.Z. and S.R.A. carried out the clinical study with bioimpedance measurement. R.M.B. performed the clinical PET. F.Z., N.W.L., and P.K. participated in the design of the study. F.Z. and P.K. wrote the manuscript. All authors read and approved the final manuscript.

\section{References}

1 Kim YL, Biesen WV. Fluid Overload in Peritoneal Dialysis Patients. Semin Nephrol. 2017 Jan;37(1):43-53.

2 Mehrotra R, Devuyst O, Davies SJ, Johnson DW. The Current State of Peritoneal Dialysis. J Am Soc Nephrol. 2016 Nov; $27(11): 3238-52$.

3 Devuyst 0, Margetts PJ, Topley N. The pathophysiology of the peritoneal membrane. J Am Soc Nephrol. 2010 Jul;21(7):1077-85.

4 Kwan BC, Szeto CC, Chow KM, Law MC, Cheng MS, Leung CB, et al: Bioimpedance spectroscopy for the detection of fluid overload in Chinese peritoneal dialysis patients. Perit Dial Int. 2014 Jun;34(4):409-16.

5 da Costa BM, Del Peso G, Bajo MA, Carreño G, Ferreira M, Ferreira C, et al. Relationship between bioimpedancedetermined body composition and peritoneal transport in peritoneal dialysis. Int J Artif Organs. 2017 May; 40(5):212-8.

6 Siriopol D, Onofriescu M, Voroneanu L, Apetrii M, Nistor I, Hogas S, et al. Dry weight assessment by combined ultrasound and bioimpedance monitoring in low cardiovascular risk hemodialysis patients: a randomized controlled trial. Int Urol Nephrol. 2017 Jan;49(1):143-53.

7 Lindley E, Devine Y, Hall L, Cullen M, Cuthbert S, Woodrow G, et al: A ward-based procedure for assessment of fluid status in peritoneal dialysis patients using bioimpedance spectroscopy. Perit Dial Int. 2005 Feb; 25 Suppl 3:S46-8.

8 Arroyo D, Panizo N, Abad S, Vega A, Rincon A, de Jose AP, Lopez-Gomez JM: Intraperitoneal fluid overestimates hydration status assessment by bioimpedance spectroscopy. Perit Dial Int. 2015 Jan-Feb;35(1):85-9.

9 Zhu F, Hoenich NA, Kaysen G, Ronco C, Schneditz D, Murphy L, et al. Measurement of intraperitoneal volume by segmental bioimpedance analysis during peritoneal dialysis. Am J Kidney Dis. 2003 Jul;42(1): 167-72.

10 Van Biesen W, Williams JD, Covic AC, Fan S, Claes K, Lichodziejewska-Niemierko M, et al.; EuroBCM Study Group. Fluid status in peritoneal dialysis patients: the European Body Composition Monitoring (EuroBCM) study cohort. PLoS One. 2011 Feb;6(2):e17148.

11 Guo Q, Yi C, Li J, Wu X, Yang X, Yu X. Prevalence and risk factors of fluid overload in Southern Chinese continuous ambulatory peritoneal dialysis patients. PLoS One. 2013;8(1):e53294.

12 Davison SN, Jhangri GS, Jindal K, Pannu N. Comparison of volume overload with cycler-assisted versus continuous ambulatory peritoneal dialysis. Clin J Am Soc Nephrol. 2009 Jun;4(6):1044-50.

13 Flythe JE, Assimon MM, Overman RA. Target weight achievement and ultrafiltration rate thresholds: potential patient implications. BMC Nephrol. 2017 Jun;18(1):185.

$14 \mathrm{Ng} \mathrm{JK}$, Li PK. Fluid management and bioimpedance study in peritoneal dialysis. Curr Opin Nephrol Hypertens. 2019 Jan;28(1):58-64.

15 Van Biesen W, Verger C, Heaf J, Vrtovsnik F, Britto ZM, Do JY, et al; IPOD-PD Study Group: Evolution Over Time of Volume Status and PD-Related Practice Patterns in an Incident Peritoneal Dialysis Cohort. Clin J Am Soc Nephrol. 2019 Jun;14(6):882-93.

16 Parthasarathy R, Oei E, Fan SL. Clinical value of body composition monitor to evaluate lean and fat tissue mass in peritoneal dialysis. Eur J Clin Nutr. 2019 Jan. https://doi.org/10.1038/s41430-019-0391-3.

17 Zhu F, Schneditz D, Kaufman AM, Levin NW. Estimation of body fluid changes during peritoneal dialysis by segmental bioimpedance analysis. Kidney Int. 2000 Jan;57(1):299-306.

18 La Milia V, Di Filippo S, Crepaldi M, Del Vecchio L, Dell'Oro C, Andrulli S, et al. Mini-peritoneal equilibration test: A simple and fast method to assess free water and small solute transport across the peritoneal membrane. Kidney Int. 2005 Aug;68(2):840-6.

19 Galach M, Antosiewicz S, Baczynski D, Wankowicz Z, Waniewski J. Sequential peritoneal equilibration test: a new method for assessment and modelling of peritoneal transport. Nephrol Dial Transplant. 2013 Feb;28(2): 447-54.

20 Neubauer M, Häntzsche E, Pamporaki C, Eisenhofer G, Dannemann M, Nocke A, et al. Development of a Function-Integrative Sleeve for Medical Applications. Sensors (Basel). 2019 Jun;19(11):19. 
21 Liakopoulos V, Dombros N: Patient selection for automated peritoneal dialysis: for whom, when? Perit Dial Int. 2009 Feb;29 Suppl 2:S102-7.

22 Amerling R, Winchester JF, Ronco C. Continuous flow peritoneal dialysis: update 2012. Contrib Nephrol. 2012; 178:205-15.

23 Heimbürger 0, Waniewski J, Werynski A, Lindholm B. A quantitative description of solute and fluid transport during peritoneal dialysis. Kidney Int. 1992 May;41(5):1320-32.

24 Cho KH, Do JY, Park JW, Yoon KW, Kim YL: The effect of low-GDP solution on ultrafiltration and solute transport in continuous ambulatory peritoneal dialysis patients. Perit Dial Int. 2013 Jul-Aug;33(4):382-90.

25 Teixido-Planas J, Troya-Saborido MI, Pedreira-Robles G, Del-Rio-Lafuente M, Romero-Gonzalez R, Bonet-Sol J: Measuring peritoneal absorption with the prolonged peritoneal equilibration test from 4 to 8 hours using various glucose concentrations. Perit Dial Int. 2014 Sep-Oct;34(6):605-11.

26 Lopes DM, Rodriguez-Carmona A, Falcon TG, Muniz AL, Hermida TF, Iglesias AL, Fontan MP: Analysis of Ultrafiltration Failure Diagnosed at the Initiation of Peritoneal Dialysis with the Help of Peritoneal Equilibration Tests with Complete Drainage at Sixty Minutes. A Longitudinal Study. Perit Dial Int. 2016 Jul-Aug;36(4):442-7. 